\title{
Transport processes of radiopharmaceuticals and -modulators
}

\author{
Thomas Efferth ${ }^{1 *}$ and Peter Langguth ${ }^{2}$
}

\begin{abstract}
Radiotherapy and radiology have been indispensable components in cancer care for many years. The detection limit of small tumor foci as well as the development of radio-resistance and severe side effects towards normal tissues led to the development of strategies to improve radio-diagnostic and -therapeutic approaches by pharmaceuticals. The term "radiopharmaceutical" has been used for drugs labeled with radioactive tracers for therapy or diagnosis. In addition, drugs have been described to sensitize tumor cells to radiotherapy (radiosensitizers) or to protect normal tissues from detrimental effects of radiation (radioprotectors). The present review summarizes recent concepts on the transport of radiopharmaceuticals, radiosensitizers, and radioprotectors in cells and tissues, e.g. by ATP-binding cassette transporters such as P-glycoprotein. Strengths and weaknesses of current strategies to improve transport-based processes are discussed.
\end{abstract}

Keywords: ABC transporter, Multidrug resistance, Radioresistance, Radioprotection, Radiochemotherapy

\section{Introduction}

Together with surgery and chemotherapy, radiotherapy represents one of the main pillars of cancer therapy. The field of radiology for image-based cancer diagnostics experiences rapid progress in the past years making both radiotherapy and -diagnostic to indispensible components in cancer care.

A number of strategies have been developed to increase efficacy of radiotherapeutic and -diagnostic approaches by pharmaceuticals. This represents exciting interdisciplinary opportunities for research in medicine and physics on the one hand and pharmacy and pharmacology on the other hand.

Traditionally, the term "radiopharmaceutical" has been used for drugs labeled with radioactive tracers for therapeutic or diagnostic purposes. Due to the enormous progress in the past decade, the interface between drug treatment and radiotherapy became much broader. Many drugs have been described to sensitize tumor cells to radiotherapy or to protect normal tissues from radiation-induced injuries. In a broader sense, those drugs are also "radiopharmaceuticals". Even drugs which

\footnotetext{
*Correspondence: efferth@uni-mainz.de

'Department of Pharmaceutical Biology, Institute of Pharmacy and

Biochemistry, Johannes Gutenberg-University, Mainz, Germany

Full list of author information is available at the end of the article
}

increase the efficacy of other forms of radiation-based therapy have to be named in this context, e.g. 8-methoxypsoralen in UVA-therapy or enhancers of photodynamic drugs. In order to avoid confusion with the term "radiopharmaceutical" in the narrow sense, we propose the term radiomodulator for drugs sensitizing tumor cells or protecting normal tissues to all forms of radiation therapy.

The multiple and partly heterogeneous aspects of radiopharmaceuticals and -modulators can be separated into three major fields:

(1) Radiopharmaceuticals are used in nuclear medicine as tracers for diagnostics and therapy of many diseases. Technetium 99m (Tc-99m) serves as gamma-rays-emitting tracer nuclide for many radiopharmaceuticals. More than 30 different Tc-99mbased radiopharmaceuticals are known, which are used for imaging and functional studies in diverse organs, e.g. brain, lung, kidneys, liver, skeleton etc. [1]. They also serve for diagnostic visualization of tumors. Moreover, numerous radiopharmaceuticals have been developed with other radioisotopes than Tc-99m. Their localization in the body is also determined by gamma-ray measurement. Radioisotopes suitable for this purpose are Fluor-18, Gallium-67,

\section{Biomed Central}


Gallium-68, Jod-124 and many more. Another interesting treatment option is boron neutron capture therapy (BNCT) which is based on the neutron capture reaction of the stable isotope ${ }^{10} \mathrm{~B}$ by irradiating this isotope with thermal neutrons $\left(E_{n}<0.1 \mathrm{KeV}\right)$, the ionized particles ${ }^{4} \mathrm{He}$ and ${ }^{7} \mathrm{Li}$ are generated from the ${ }^{10} \mathrm{~B}(\mathrm{n}, \alpha)^{7} \mathrm{Li}$ reaction [2]. Preloading of cells with specific markers can be used for the treatment of specific cancer types [3].

(2) Radiosensitizers: About one half of all patients with a solid tumor are treated by radiotherapy. The effectiveness of this treatment option is, however, frequently hampered by the development of radioresistance [4]. Therefore, the combination of radiotherapy with drugs to sensitize tumors towards radiotherapy is an attractive strategy [5,6]. At the same time, the radiation effects on normal tissues should not be increased by radio-sensitizing agents.

Ionizing radiation causes DNA damage by the generation of reactive oxygen species (ROS), especially DNA double strand breaks. Diverse established anticancer agents have been described to sensitize tumors towards radiotherapy by interaction with DNA biosynthesis (5fluorouracile, gemcitabine, hydroxyurea) [7] or inhibition of DNA-replication and repair by adduct formation (temozolomide, cisplatin) [8,9]. DNA topoisomerase inhibitors (topotecan, irinotecan) have also been shown to exert radio-sensitizing effects [10]. Mitotic spindle poisons (paclitaxel, docetaxel) arrest tumor cells in the $\mathrm{G}_{2} \mathrm{M}$ phase of the cell cycle[11].

Frequently, hypoxic areas are found in tumors. As oxygen is necessary for the formation of radical molecules, which are important in radiotherapy, hypoxic tumors are radio-resistant. Various strategies have been advised to overcome this problem, e.g. re-oxygenation of hypoxic tumors (nitroimidazole compounds, efaproxiral), the activation of intracellular reductases by bioreductive cell poisons (tirapazamine) or the inhibition of the hypoxia-inducing factor (HIF-1) [12,13]. HIF-1 inhibitors are more in the focus of interest, as nitroimidazoles reveal a narrow therapeutic window.

In the past years, rational radio-sensitizing concepts have been investigated, which are based on the inhibition of specific target proteins [14]. Examples are inhibitors of specific repair enzymes for radiation-induced damage (ATM kinase), DNA-PK, Chk1 and Parp-1 (e.g. caffeine, $[15,16]$ as well as inhibitors of epidermal growth factor receptor (EGFR) pathway (cetuximab, erlotinib) and inhibitors of downstream signaling routes (wortmannin). Radio-sensitizing effects have also been observed by inhibitors of the NF- $\kappa \mathrm{B}$ transcription factor and substances, which switch off radiation-induced apoptosis (p53 modulators, Bcl-2 inhibitors).
Trichostatin A inhibits histone deacetylases and geldanamycin blocks the heat shock protein, HSP90. The suppression of blood vessel formation in tumors (neoangiogenesis) gained much attention in the past years. Interestingly, various angiogenesis inhibitors, e.g. blockers of the vascular endothelial growth factor (VEGF) also exert radio-sensitizing effects.

Special forms of radiosensitizers are photosensitizers, i.e. chemical compounds excited by visible or near-infrared light. If accumulated in tumors and illuminated by light, photo-sensitizers generate singlet oxygen destroying tumor cells [17-19]. Broadband ultraviolet B (BBUVB), and psoralen plus and ultraviolet A (PUVA), and more recently narrowband UVB (NB-UVB) are skindirected phototherapies used to treat cutaneous $\mathrm{T}$-cell lymphoma. Extracorporeal photopheresis (ECP) is effective in more advanced stage disease [20-22].

In photodynamic therapy (PDT), photosensitizers such as photofrin are excited by light of a specific wavelength. Interestingly, some types of photosensitizers are substrates of Breast Cancer Resistance Protein (BCRP, ABCG2) leading to resistance of tumors to PDT [23]. For example, A431 lung cancer cells transfected with BCRP were more resistant to photofrin-PDT than A431 control cells in vitro and fumitremorgin $C$, a specific BCRP inhibitor, reversed this resistance [24]. A clinical study with 81 lung cancer patients showed that the efficacy of photofrin-PCT in cancer lesions was significantly affected by the expression of BCRP [24].

Genetic polymorphisms and transcriptional activation in the ABCG2 (BRCP) transporter influenced cellular accumulation of porphyrin derivatives in cancer cells leading to individual differences of patients in their response to photodynamic therapy [23].

(3) Radioprotectors: Protection from radiationinduced damage is important to

- avoid radiation damage in healthy tissue and organs during radiotherapy of tumors

- save personnel of airlines from excessive exposure to radiation in the air.

Various natural products and synthetic compounds have been described as radioprotectors [25]. They can be separated in four categories:

(a) Scavenger of ROS and other radical molecules. Selen and selenoproteins exert anti-oxidant, radioprotective and anti-carcinogenic effects. A possible effector of this radio-protective effect is glutathione peroxidase. This opens the possibility that nutritional supplementation with L-selenomethionine might represent a suitable radioprotector for airline personnel [26]. 
(b) Further radio-protective nutritional supplements are $\mathrm{N}$-acetyl-L-cysteine (NAC), tocopherol succinate (a vitamin $\mathrm{E}$ analogue) and eugenol. Resveratrol and other polyphenols activate Sirt1 expression. Sirtuins are $\mathrm{NAD}^{+}$-dependent deacetylases, which interact with the NBS1 DNA repair protein, thereby regulating DNA damage repair. Furthermore, resveratrol suppresses inflammatory processes by inhibition of prostaglandin production, COX2 expression and $\mathrm{NF} \kappa \mathrm{B}$ activity. Resveratrol also induces $\mathrm{G} 1$ and G1/S cell cycle arrest and apoptosis [26,27].

(c) Manganese-dependent superoxide dismutase (MnSOD) is an anti-oxidant enzyme. Small molecule MnSOD inhibitors and gene-therapeutic strategies based on MnSOD have been described to lower cellular ROS levels for radio-protection [27].

(d) Amifostine and its active metabolite, WR-1065, are non-protein-thiols, scavenging ROS and other radical molecules. Thereby, they support DNA damage repair and influence intracellular hypoxia by auto-oxidation processes [27].

(e) Improvement of DNA damage repair and modulation of signal transduction after DNA damage. Amifostine also inhibits DNA topoisomerase II leading to the arrest of damaged cells in the $\mathrm{G}_{2} \mathrm{M}$ phase of the cell cycle. Thereby, the homologous recombination DNA repair pathway in the $G_{2} M$ phase is more effective [27].

(f) Inhibition of apoptosis in radiation-damaged cells. Flagellin is a natural product of bacteria. The flagellin derivative, CBLB502, activates $\mathrm{NF} \kappa \mathrm{B}$ via the tolllike receptor-5 (TLR-5) and inhibits the onset of apoptosis. The synthetic small molecule, PD 0332991 inhibits CDK-4 and -6 and protects from radiation damage by induction of Ras-mediated cellular quiescence and inhibition of apoptosis [28,29].

\section{Transport through bio-membranes}

The first barrier for drugs represents the entry from the body surface to the body inside (absorption). In this context, the inside of the gastrointestinal tract is understood as body surface. The cellular structures separating the outside of the body from the inside are lipid bilayerconsisting cell membranes. Hence, the passage through bio-membranes is a precondition for drug activity.

This can happen by diverse mechanisms [30]:

(1) Lipophilic substances enter cell membranes by passive diffusion or passive transport (carrier) without energy, i.e. ATP consumption.

(2) Hydrophilic compounds enter cell membranes by passive transport (e.g. ion channels) or active transport (ATP-consuming transport).
(3) For vesicular transport, extracellular compounds are included into vesicles, which constrict into the intracellular space (phagocytosis, pinocytosis).

(4) For receptor-mediated endocytosis, compounds bind to receptors on the cell surface. Receptorligand-complexes are accumulated in coated pits of the cell membrane and are internalized by endocytosis.

There are three super-families of ATP-consuming transporters with eminent relevance for drug transport:

(1) ATP-binding cassette $(A B C)$ transporter. This family consists of 49 members in the human genome [31-33]. The multidrug resistance-mediating transporters P-glycoprotein ( $A B C B 1, M D R 1)$, multidrug resistance-related proteins (ABCC, MRP), and the breast cancer resistance protein (ABCG2, BCRP) belong to this family $[34,35]$. They confer resistance towards anticancer drugs in tumors. In healthy tissues and organs they have a protective function towards xenobiotic compounds, e.g. in the bloodbrain-barrier [36].

(2) The solute carrier (SLC) superfamily contains members with very diverse functions. The subfamilies, SLC6A, 10A, 15A, 16A, 17A, 22A and $29 \mathrm{~A}$ are associated with the transport of xenobiotics. These subfamilies consist of organic anion transporters, organic cation transporters, nucleoside transporters, amino acid and peptide transporters [37].

(3) The sodium-independent large organic anion transporters (SLCO) are a third superfamily involved in drug transport. Previously, they were assigned to the SLC superfamily as SLC21A subfamily, but now they consist of an own gene family $[38,39]$.

In addition to drug uptake, the distribution in tissues and organs are essential for drug activity. Drugs are frequently bound to transfer proteins. As an example, albumin binds many different free drug molecules in the blood. Moreover, there are more specific transfer molecules, which only bind certain drug classes, e.g. $\alpha$-tocopherol-binding proteins or transferrin, which binds iron and enables its uptake into cells $[40,41]$.

Unambiguously, drug transport is of eminent importance for drug activity. This is true for radiopharmaceuticals as well as radiomodulators. There was a thriving development in this field in the past years, which is a fertile ground for exciting novel research concepts in the years to come. A synopsis of cellular transport processes described in this review is depicted in Figure 1. 


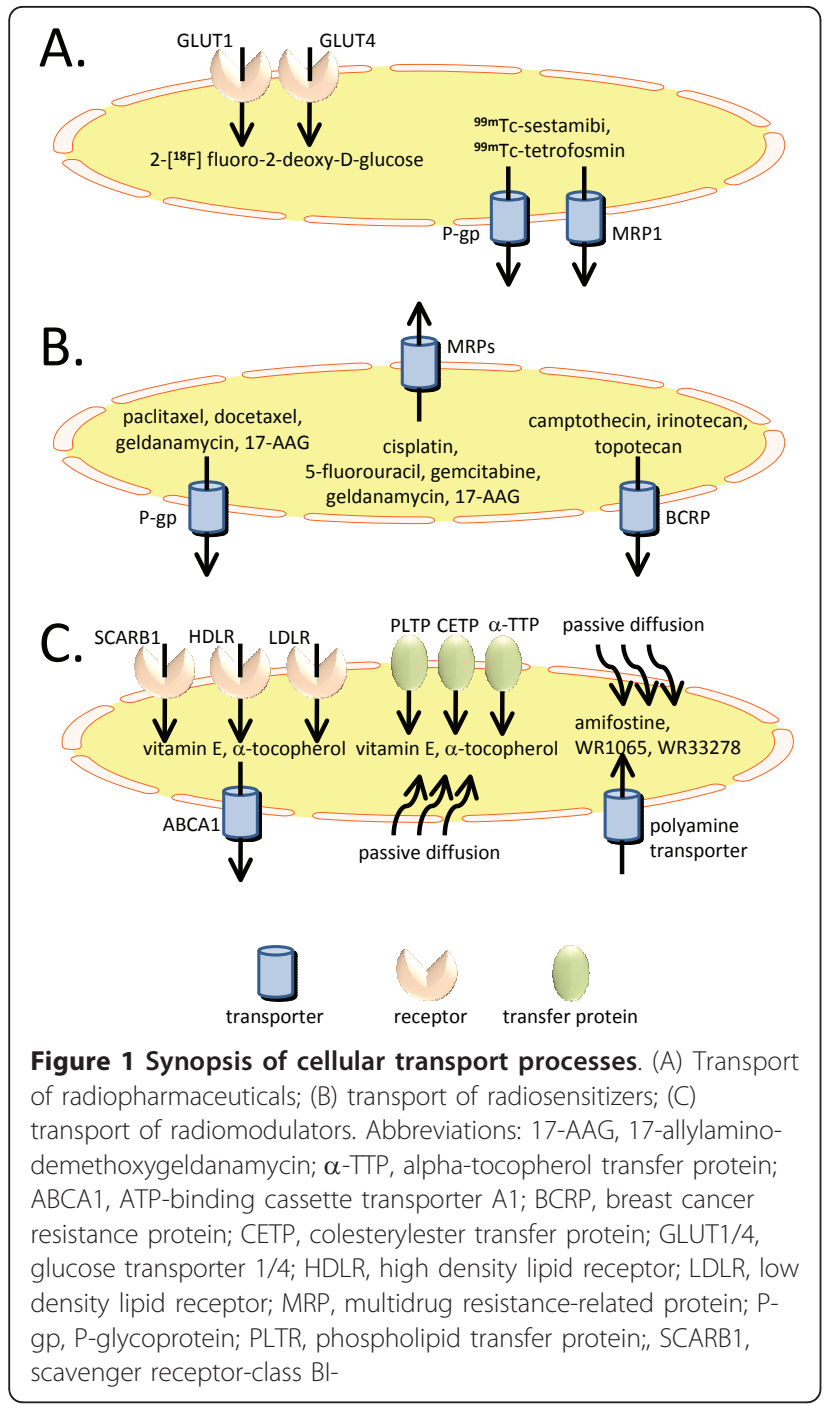

\section{Transport of radiopharmaceuticals}

A well-known radiotracer for positron emission tomography (PET) is 2- $\left[{ }^{18} \mathrm{~F}\right]$ fluoro-2-deoxy-D-glucose (FDG) (Figure 2). Tumor imaging by FDG-PET is based on a fundamental observation of Otto Warburg in the first half of the $20^{\text {th }}$ century. He found that cancer cells take up more glucose than normal cells. Despite reduced oxygen consumption, they have higher glycolysis rates [42]. FDG is taken up by tumor cells via the glucose transporters, GLUT1 and GLUT4. Intracellularly, FDG is phosphorylated to FDG-6-phosphate without further metabolization. Thereby, it is accumulated more in tumors than in normal surrounding tissues. Tumor cells express more GLUT1 than normal cells.

Though FDG-PET is already established in clinical routine diagnostics [43], there are several problems. The GLUT1 expression largely varies from tumor type to tumor type affecting FDG uptake. Proliferation rate,

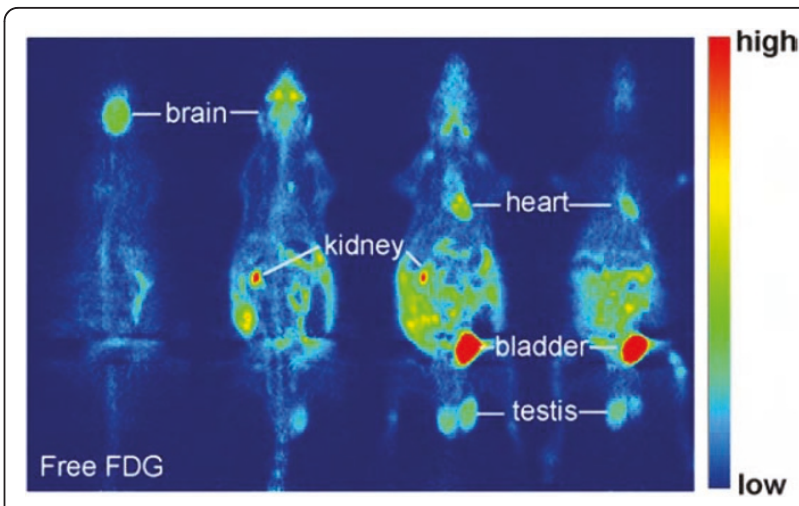

Figure $\mathbf{2}$ Whole body images $\mathbf{2}$ h after i.p. injection (horizontal slices, thickness $7 \mathbf{~ m m}$ ). Free $\left.{ }^{18} \mathrm{~F}\right] \mathrm{FDG}$ is taken up by high-glucose using cells such as brain, heart and testis and excreted via kidney and bladder. Liposomal encapsulated ${ }^{18}$ F]FDG accumulates in the abdomen of the rat. Only released $\left[{ }^{18} \mathrm{~F}\right] \mathrm{FDG}$ can be taken up into organs (Picture taken from [41]).

hypoxia, inflammatory infiltrates and even blood sugar level all influence FDG uptake. Hence, there is an urgent need for novel radiotracers with more specific target properties [44].

The sodium-iodide symporter (NIC) uses the sodium gradient built up by sodium-potassium ATPase in the cell membrane for the co-transport of iodide and sodium into the cell. This co-transport can be especially observed in the pituitary, lactating breast epithelia as well as sweat glands and in stomach mucosa [45]. Therefore, these tissues accumulate the radioactive isotopes, ${ }^{123} \mathrm{I}$ and ${ }^{131} \mathrm{I}$ as well as ${ }^{99 \mathrm{~m}} \mathrm{Tc}$-pertechnetates. This can be used in nuclear medicine for diagnosis and therapy of pituitary diseases [46].

P-glycoprotein $(A B C B 1, M D R 1)$ is well-known in terms of its function for multidrug resistance of tumors [31,33]. Two major therapy concepts have been developed with P-glycoprotein as target molecule:

- Pharmacological inhibition of P-glycoprotein and, thereby, the re-sensitization of multidrug-resistance - MDR1- based gene therapy of healthy bone marrow cells to confer resistance towards high-dose chemotherapy. High concentrations of anticancer drugs would kill tumor cells but spare healthy bone marrow because of the gene therapeutic MDR1 expression.

For both concepts, non-invasive molecular imaging techniques are desired to predict and monitor treatment success. For this purpose, various $\gamma$-ray-emitting substances have been developed, which are transport substrates of P-glycoprotein. The best-known radiopharmaceuticals in this context are ${ }^{99 \mathrm{~m}} \mathrm{Tc}$-sestamibi $[47,48]$ and ${ }^{99 \mathrm{~m}} \mathrm{Tc}-$ Tetrofosmin [49]. P-glycoprotein- 
expressing multidrug-resistant tumor cells extrude both compounds out of the cell whereas P-glycoprotein-negative, drug-sensitive tumor cells accumulate the substances. This uptake can be visualized as hot spots by scintigraphy. The realization of this strategy has been demonstrated in several proof-of-principle clinical trials. The conclusion of these studies was that both substances are able to predict multidrug-resistance of tumors caused by P-glycoprotein [50-53]. ${ }^{99 \mathrm{~m}} \mathrm{Tc}$-sestamibi revealed $\mathrm{P}$-glycoprotein specificity in cancer patients. An MRP1-related transport of this compound could not be detected, although this was observed in preclinical models in vitro $[49,54] .{ }^{99 \mathrm{~m}} \mathrm{Tc}$-Tetrofosmin was also found to be transported by MRP1 in vitro $[54,55]$. In a clinical trial, ${ }^{99 \mathrm{~m}} \mathrm{Tc}-\mathrm{MIBI}$ accumulation in patients correlated with the absence of both P-glycoprotein and MRP1 expression, indicating that ${ }^{99 \mathrm{~m}} \mathrm{Tc}-\mathrm{MIBI}$ is also transported by MRP1 [56]. Similar results have been found for ${ }^{99 \mathrm{~m}} \mathrm{Tc}$-Tetrofosmin in lymphoma patients [57].

\section{Transport of radiosensitizers}

Many established anticancer agents used to sensitize radiation effects in combined radiochemotherapy are substrates of drug transporters. Mitotic spindle poisons such as paclitaxel and docetaxel are well-known substrates of P-glycoprotein. Camptothecin derivatives (topotecan, irinotecan) are transported by BCRP (ABCG2). Multidrug resistance-related proteins of the $A B C C$ subfamily of $A B C$ transporters confer resistance towards cisplatin, 5-fluorouracil and gemcitabine. Moreover, copper transporters (e.g. CTR1) and volume-sensitive chloride channels also contribute to cisplatin resistance. Changes of membrane fluidity are a further factor of drug resistance. In as much as transport processes influence drug resistance, they also affect radiosensitizing effects in combined radiochemotherapy, since necessary drug levels are not reached in tumors.

Ionizing radiation has been shown to enhance cellular resistance to anticancer drugs, including methotrexate, 6 -thioguanine, cisplatin and others $[58,59]$. Hill et al. were the first to report that in vitro exposure of mammalian cells to fractionated irradiation results in the expression of a multidrug resistance phenotype with cross-resistance to Vinca alkaloids, epipodophyllotoxins and colchicine, but not to anthracyclines [60]. These cell lines revealed an overexpression of P-glycoprotein, but not of MDR1 mRNA. Studies to elucidate the reason for increased protein but unchanged mRNA levels upon Xirradiation revealed a slower turnover of P-glycoprotein in X-irradiated cells(half life: $40 \mathrm{~h}$ ) relative to classical drug-selected sublines (half life: $17 \mathrm{~h}$ ), indicating that Pglycoprotein gp overexpression may be differently regulated in these sublines at the translational level [61].
These data clearly show that the development of drug resistance following $\mathrm{X}$-irradiation arise by a mechanism distinct from that operating after drug selection. Fractionated irradiation of a human epidermoid lung carcinoma xenograft grown in nude mice also results in overexpression of P-glycoprotein without concomitant MDR1 mRNA overexpression [62]. This in vivo approach mimics the clinical situation and points to a possible role of irradiation for P-glycoprotein overexpression and induction of drug resistance in radiochemotherapy. Subsequently, similar results have been found for MRP1. Fractionated X-irradiation increased resistance of tumor cell lines to anticancer drugs and induced expression of MRP1 [63-65].

Nitroimidazoles have been coupled to sugar molecules, since hypoxic tumors reveal higher glycolysis and higher membrane transporter-mediated glucose uptake [66]. Hybrid molecules of sugars and nitroimidazoles (e.g. TX-2224) showed increased cellular uptake and at the same time radio-sensitizing activity [67]. Similarly, ifosfamide has been coupled to sugars (glufosfamide) to sensitize hypoxic tumors for radiochemotherapy [68]. Increased glucose uptake in hypoxic and radio-resistant tumors is also the rationale for using 2-deoxy-D-glucose (2-DG). This compound inhibits the first enzyme of glycolysis (hexokinase), increases metabolic oxidative stress in tumor cells and sensitizes tumor cells towards radiation [69,70]. Many natural products have been described to exert radiosensitizing effects and affect function and expression of transport proteins at the same time. For instance, the radiosensitizing trichostatin A down-regulates P-glycoprotein (MDR1) expression [71].

On the other hand, over-expression of $M D R 1$ or $M R P 1$ confers resistance towards geldanamycin and its derivative, 17-allylamino-demethoxygeldanamycin (17AAG) $[72,73]$. Both compounds reveal radio-sensitizing effects by inhibition of the heat shock protein, HSP90.

Wortmannin inhibits the P-glycoprotein function [74], and a wortmannin-dependent PI3K/Akt inhibition correlates with reduced MRP1 expression [75]. Interestingly, wortmannin also inhibits the insulin-induced activation of the GLUT4 glucose transporter [76]. Glucose transporters are of prognostic value as reported for ovarian carcinoma [77]. Poorly differentiated tumors showed a trend to over-express the GLUT1 protein compared with the more differentiated counterparts. Patients who experienced a complete clinical response to chemotherapy were more frequently GLUT1 positive than GLUT1 negative. In multivariate analysis of advanced stage disease, residual tumor and high GLUT1 expression levels were the only independent variables that maintained a significant association with response to chemotherapy. In Stage III-IV patients showing a 
complete clinical response, GLUT1 over-expression was associated with a shorter disease-free survival.

Resveratrol and many other polyphenolic compounds inhibit P-glycoprotein and other $\mathrm{ABC}$ transporters in terms of function and expression $[78,79]$. The fact that resveratrol and other flavonoids act as inhibitors of Pglycoprotein raised much interest, because clinical trials with synthetic compounds to modulate the function of P-glycoprotein were not very promising yet $[80,81]$. Most of these resistance-modifying agents are too toxic at the required doses. Therefore, the search for P-glycoprotein inhibitors from the field of natural products may be more promising, since many natural products and phytotherapeutics are appreciated for their low side effects and good tolerability. As P-glycoprotein detoxifies xenobiotic compounds in normal tissues taken up with food, it can be expected that many herbal compounds are substrates of this efflux transporter. Indeed, there is a large body of evidence that natural compounds are transported by P-glycoprotein. From an evolutionary point of view, substrates and inhibitors of Pglycoprotein have been frequently co-developed in the same plant species. Plants developed secondary metabolites during evolution of life to defend against predators such as herbivores. If herbivores detoxify harmful natural products by P-glycoprotein, plants need inhibitors of P-glycoprotein for efficient self-defense. Hence it can be speculated that many $\mathrm{P}$-glycoprotein inhibitors should be present in plants [82]. During the past years, P-glycoprotein-inhibiting activities have frequently been observed. The large number of data can be separated in two major categories: natural products either functionally inhibit P-glycoprotein by interference with efflux activity of the drug pump or they down-regulate P-glycoprotein/MDR1 expression, thereby re-sensitizing multidrug-resistant cells [83]. Some of these compounds inhibit not only P-glycoprotein, but also MRP1 [84-86] or BCRP [86-88]. It has not yet unequivocally been clarified, whether large amounts of polyphenols taken up with fruits and vegetables may influence absorption, distribution, and secretion of drugs in general or radiosensitizers.

\section{Transport of radioprotectors}

The use of radioprotective agents in cancer therapy raises the question, how normal tissues, but not tumors can selectively be protected. Specific transport process may be helpful for the development of such strategies.

Amifostine (WR-2721) and its derivatives are phosphoaminothionates. As pro-drugs, they are dephosphorylated by alkaline phosphatase. The metabolite, WR 1065, passively diffuses through the cell membrane and is oxidized to a disulfide, WR-33278. As this compound reveals chemical similarity to polyamine spermine, it is then transported by the ornithine decarboxylase (ODC)-antizyme (OAZ)-dependent polyamine transporter leading to cellular accumulation of amifostine derivatives [90,91]. A selective radioprotection of normal but not tumor cells may be achieved by transfection of $O A Z$ cDNA. Thereby, the polyamine transporter and, hence, WR-33278 uptake is inhibited. Since tumor cells reveal higher ODC activities and polyamine contents as normal tissues, a combination therapy of amifostine and $O A Z$ gene transfer may result in an increased eradication of tumor cells with protection of normal tissues at the same time [92].

The topical application of radioprotectors in the form of creams and ointments for airline employees, depends on dermal absorption. The passage through the Stratum corneum to the epidermis and dermis is not only influenced by the radio-protecting agent itself, but also by the formulation, as shown for amifostine (WR-2721) [93].

Remarkably, radiosensitivity also depends on the expression of drug transporters independently of a simultaneous application of radio-protective or radiosensitizing agents. The retroviral transfer of the MDR1 gene induced differential expression of genes, including up-regulation of detoxifying and down-regulation of pro-apoptotic genes [94]. Hence, it can be speculated that MDR1-based gene therapy as well as induction of $M D R 1$ gene expression by chemical agents (e.g. small molecules) may favor the protection of normal tissues from radiation-induced damage [95] (Figure 3).

The efficacy of radiochemotherapy is also determined by transporter-independent processes. In response to gamma-ray, whole body irradiation, changes in the intestinal membrane fluidity and lipid peroxidation have been observed [96]. Membrane fluidity is an important factor for the cellular uptake and accumulation of drugs.

Vitamin $\mathrm{E}$ and its main isomer, $\alpha$-tocopherol are very hydrophobic and cannot be freely distributed in the blood stream. Rather, they associate with lipoproteins sharing many features with lipoprotein metabolism and cholesterol transport $[97,98]$. In addition to passive diffusion in the colon, active uptake by the transmembrane glycoprotein, scavenger receptor-class BI (SCARB1, SRBI), plays a role. The microsomal triglyceride transfer protein is required for enterocytic secretion of vitamin $\mathrm{E}$ into chylomicrons. Apparently, different transport systems are necessary for tissue distribution. In addition to SR-BI, tocopherol-associated proteins (TAP), phospholipid transfer protein (PLTP) and various other transport and transfer proteins of the lipid and cholesterol metabolism have been described, e.g. the ABCA1 transporter, the cholesterylester transfer protein (CETP), LDL-and HDL- receptors and others. SR-BI also plays a role for the selective $\alpha$-tocopherol uptake across the blood brain 

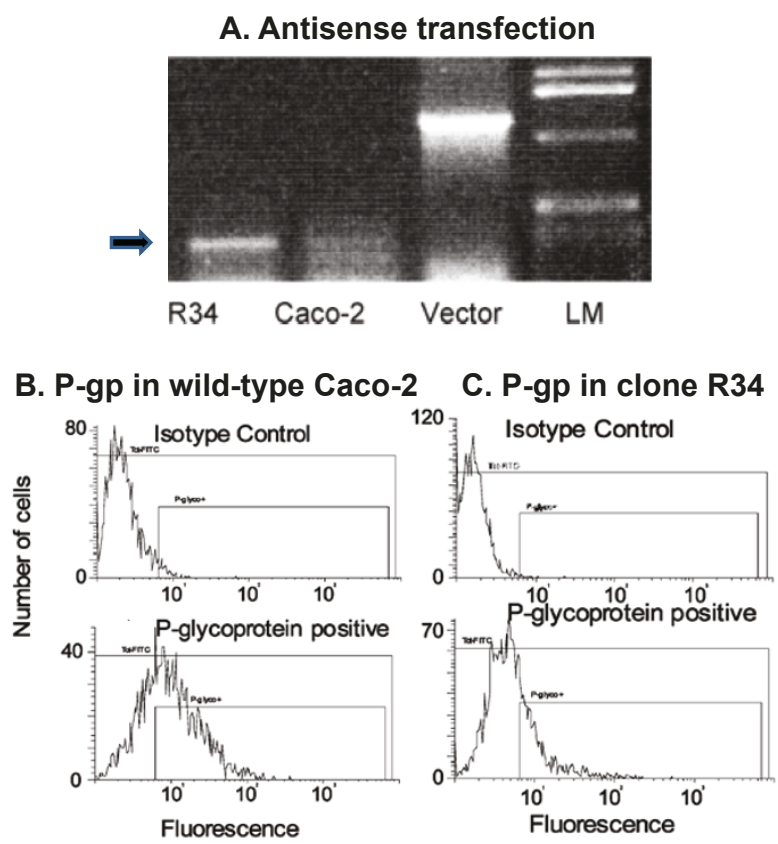

Figure 3 MDR1 antisense-mediated down-regulation of $\mathrm{P}$ glycoprotein (P-gp). (A) RT-PCR reactions on mRNA from wild-type Caco-2 cells and Caco-2 subclone R34, generated by transfection with MDR1 antisense gene cloned into the pEUK-c1 vector. A specific band (arrow) of antisense MDR1 mRNA was found in clone R34. Parental Caco-2 cells did not show this amplification product. The positive control PCR on the pEUK-c1-RDM vector gives a product 965 bases longer, as the vector contains an intron. (LM) ladder marker, representing different molecular lengths). FACS analysis of (B) wild-type Caco-2 cells and (C) MDR1-antisense transfectants R34 for the expression of P-glycoprotein. The cells were incubated with an non-specific mouse-antibody and FITClabeled anti-mouse-antibody (isotype control), and specifically labeled with the monoclonal antibody MRK16 and FITC-labeled antimouse-antibody (P-gp expression). Isotype control analysis did not reveal significant numbers of cells that would be considered P-gp positive. Compared to non-transfected cells (79.4\%), the Pglycoprotein expression in clone R34 was significantly reduced (41.8\%) (Pictures taken from [73]).

barrier and the blood-retina-barrier. The hepatic uptake occurs via the $\alpha$-tocopherol transfer protein ( $\alpha$-TTP).

The excretion takes place via bile and urine. $A B C$ transporters in the canalicular membranes of hepatocytes contribute to biliary excretion. $\alpha$-tocopherol is excreted as carboxyethyl-hydroxychromane.

\section{Conclusions and Perspectives}

Taking the research progress in this field into consideration, a number of issues appear that have not adequately been addressed as yet:

(1) The relationships between drug and radio-resistance are incompletely understood. The elucidation of underlying molecular mechanisms is necessary to take advantage of synergistic effects for tumor therapy and of antagonistic effects to protect healthy tissues. Transport process plays an eminent role in this context. Solid data are available for P-glycoprotein providing evidence for the relevance of transport processes of radiopharmaceuticals and -modulators. The vast majority of other transport proteins have been scarcely investigated and their role for radiotherapy and radiochemotherapy is not understood yet.

(2) Many single results provide strong evidence for the importance of transport processes for radiopharmaceuticals and-modulators. However, a systematic synopsis integrating and validating existing single results is still missing. This may, however, be relevant for the realization of novel diagnostic and therapeutic strategies.

(3) The translation of results of basic research to the clinical everyday routine has to be considerably improved and accelerated from our point of view. The radiotracer and P-glycoprotein substrate $\mathrm{Tm}^{99}$ sestamibi is a suitable example to illustrate the clinical relevance of transport processes of radiopharmaceuticals. There is an enormous potential for other applications in radiology and nuclear medicine based on drug transport. The inter-connection of theoretical and experimental expertise in this field represents a critical mass to foster the progress for novel diagnostic and therapeutic approaches.

\section{Author details}

'Department of Pharmaceutical Biology, Institute of Pharmacy and Biochemistry, Johannes Gutenberg-University, Mainz, Germany. ${ }^{2}$ Department of Pharmaceutical Technology and Biopharmacy, Institute of Pharmacy and Biochemistry, Johannes Gutenberg-University, Mainz, Germany.

\section{Authors' contributions}

TE and PL equally wrote this review article. Both authors read and approved the final manuscript.

\section{Competing interests}

The authors declare that they have no competing interests.

Received: 18 February 2011 Accepted: 6 June 2011

Published: 6 June 2011

\section{References}

1. Schwochau K: Technetium. Wiley-VCH; 2000.

2. Barth RF, Coderre JA, Graca Vicente MH, Blue TE: Boron neutron capture therapy of cancer: current status and future prospects. Clinical Cancer Research 2005, 11:3987-4002.

3. Werner S, Schütz C, Grunewald C, Hampel G, Kratz J-V, Nawroth T, Peters T, Langguth P: Enhancement of boronophenylalanine uptake into human hepatoma cells by preloading with L-DOPA and L-tyrosine..

4. Efferth T, Fabry U, Osieka R: Apoptosis and resistance to daunorubicin in human leukemic cells. Leukemia 1997, 11:1180-1186.

5. Bischoff $P$, Altmeyer A, Dumont F: Radiosensitising agents for the radiotherapy of cancer: advances in traditional and hypoxia targeted radiosensitisers. Expert Opinion on Therapeutic Patents 2009, 19:643-662.

6. Konkimalla VB, Efferth T: Molecular mechanisms and interactions responsible for radio- and chemoresistance of tumors and their modulation by natural products from Ayurveda. In Herbal medicine. A 
cancer chemopreventive and therapeutic perspective. Edited by: Arora R. Jaypee Brothers Medical Publishers Pvt. Ltd, New Delhi, St. Louis (USA); 2010:513-530.

7. Shewach DS, Lawrence TS: Antimetabolite radiosensitizers. Journal of Clinical Oncology 2007, 25:4043-4050.

8. Kelland L: The resurgence of platinum-based cancer chemotherapy. Nature Reviews Cancer 2007, 7:573-584.

9. Kil WJ, Cerna D, Burgan WE, Beam K, Carter D, Steeg PS, Tofilon PJ, Camphausen $\mathrm{K}$ : In vitro and in vivo radiosensitization induced by the DNA methylating agent temozolimide. Clinical Cancer Research 2008, 14:931-938.

10. Wardman P: Chemical radiosensitizers for use in radiotherapy. In Clinical Oncology. Volume 19. Royal College of Radiologists, Great Britain; 2007:397-417.

11. Seiwert TY, Salama JK, Vokes EE: The concurrent chemoradiation paradigm-general principles. Nature Clinical Practice Oncology 2007, 4:86-100.

12. Brown JM: Tumor hypoxia in cancer therapy. Methods in Enzymology 2007, 435:297-321.

13. Overgaard J: Hypoxic radiosensitization: adored and ignored. Journal of Clinical Oncology 2007, 25:4066-74.

14. Dumont F, Altmeyer A, Bischoff P: Radiosensitising agents for the radiotherapy of cancer: novel molecularly targeted approaches. Expert Opinion on Therapeutic Patents 2009, 19:775-799.

15. Efferth T, Fabry U, Glatte P, Osieka R: Expression of apoptosis-related oncoproteins and modulation of apoptosis by caffeine in human leukemic cells. Journal of Cancer Research and Clinical Oncology 1995 121:648-56.

16. Tenzer A, Pruschy M: Potentiation of DNA-damage-induced cytotoxicity by $\mathrm{G} 2$ checkpoint abrogators. Current Medicinal Chemistry. Anticancer Agents 2003, 3:35-46

17. Allison RR, Sibata $\mathrm{CH}$ : Photodynamic therapy: mechanism of action and role in the treatment of skin disease. Giornale Italiano Dermatologia e Venereologia 2010, 145:491-507.

18. Verhille M, Couleaud P, Vanderesse R, Brault D, Barberi-Heyob M, Frochot C: Modulation of photosensitization processes for an improved targeted photodynamic therapy. Current Medicinal Chemistry 2010, 17:3925-3943.

19. Hariharan M, Karunakaran SC, Ramaiah D, Schulz I, Epe B: Photoinduced DNA damage efficiency and cytotoxicity of novel viologen linked pyrene conjugates. Chemical Communications (Cambridge, England) 2010, 46:2064-2066.

20. Efferth T, Fabry U, Osieka R: Induction of apoptosis, depletion of glutathione, and DNA damage by extracorporeal photochemotherapy and psoralen with exposure to UV light in vitro. Anticancer Research 2001, 21:2777-2783.

21. Shephard SE, Langguth P, Panizzon RG: Pharmacokinetic behaviour of sublingually administered 8-methoxypsoralen for PUVA therapy. Photodermatology, Photoimmunology and Photomedicine 2001, 17:11-21.

22. Pothiawala SZ, Baldwin BT, Cherpelis BS, Lien MH, Fenske NA: The role of phototherapy in cutaneous T-cell lymphoma. Journal of Drugs in Dermatology 2010, 9:764-772.

23. Ishikawa T, Nakagawa H, Hagiya Y, Nonoguchi N, Miyatake S, Kuroiwa T: Key role of human $A B C$ transporter $A B C G 2$ in photodynamic therapy and photodynamic diagnosis. Advances in Pharmacological Sciences 2010 2010:587306.

24. Usuda J, Tsunoda Y, Ichinose S, Ishizumi T, Ohtani K, Maehara S, Ono S, Tsutsui H, Ohira T, Okunaka T, Furukawa K, Sugimoto $Y$, Kato H, Ikeda N: Breast cancer resistant protein (BCRP) is a molecular determinant of the outcome of photodynamic therapy (PDT) for centrally located early lung cancer. Lung Cancer 2010, 67:198-204

25. Gudkov AV, Komarova EA: Radioprotection: smart games with death. The Journal of Clinical Investigation 2010, 120:2270-2273.

26. Girdhani S, Bhosle SM, Thulsidas SA, Kumar A, Mishra KP: Potential of radiosensitizing agents in cancer chemo-radiotherapy. Journal of Cancer Research and Therapeutics 2005, 1:129-31.

27. Dziegielewski J, Goetz W, Baulch JE: Heavy ions, radioprotectors and genomic instability: implications for human space exploration. Radiation and Environmental Biophysics 2010, 49:303-316.

28. Burdelya LG, Krivokrysenko VI, Tallant TC, Strom E, Gleiberman AS, Gupta D, Kurnasov OV, Fort FL, Osterman AL, Didonato JA, Feinstein E, Gudkov AV:
An agonist of toll-like receptor 5 has radioprotective activity in mouse and primate models. Science 2008, 320:226-230.

29. Johnson SM, Torrice CD, Bell JF, Monahan KB, Jiang Q, Wang Y, Ramsey MR, Jin J, Wong KK, Su L, Zhou D, Sharpless NE: Mitigation of hematologic radiation toxicity in mice through pharmacological quiescence induced by CDK4/6 inhibition. The Journal of Clinical Investigation 2010, 120:2528-2536.

30. Efferth T: Molekulare Pharmakologie und Toxikologie. Springer Verlag, Heidelberg; 2006.

31. Efferth T: The human ATP-binding cassette transporter genes: from the bench to the bedside. Current Molecular Medicine 2001, 1:45-65.

32. Gillet JP, Efferth T, Steinbach D, Hamels J, de Longueville F, Bertholet V, Remacle J: Microarray-based detection of multidrug resistance in human tumor cells by expression profiling of ATP-binding cassette transporter genes. Cancer Research 2004, 64:8987-8993.

33. Gillet JP, Efferth T, Remacle J: Chemotherapy-induced resistance by ATPbinding cassette transporter genes. Biochimica et Biophysica Acta 2007, 1775:237-262.

34. Efferth T, Gillet JP, Sauerbrey A, Zintl F, Bertholet V, de Longueville F, Remacle J, Steinbach D: Expression profiling of ATP-binding cassette transporters in childhood T-cell acute lymphoblastic leukemia. Molecular Cancer Therapeutics 2006, 5:1986-1994.

35. Steinbach D, Gillet JP, Sauerbrey A, Gruhn B, Dawczynski K, Bertholet V, de Longueville F, Zintl F, Remacle J, Efferth T: ABCA3 as a possible cause of drug resistance in childhood acute myeloid leukemia. Clinical Cancer Research 2006, 12:4357-4363.

36. Mahringer A, Karamustafa S, Klotz D, Kahl S, Konkimalla VB, Wang $Y$, Wang J, Liu HY, Boechzelt H, Hao X, Bauer R, Fricker G, Efferth T: Inhibition of P-glycoprotein at the blood-brain barrier by phytochemicals derived from traditional Chinese medicine. Cancer Genomics and Proteomics 2010, 7:191-205.

37. Zhang EY, Knipp GT, Ekins S, Swaan PW: Structural biology and function of solute transporters: implications for identifying and designing substrates. Drug Metabolism Reviews 2002, 34:709-750.

38. Hagenbuch B, Meier PJ: Organic anion transporting polypeptides of the OATP/SLC21 family: phylogenetic classification as OATP/SLCO superfamily, new nomenclature and molecular/functional properties. Pfluegers Archiv: European Journal of Physiology 2004, 447:653-665.

39. Hagenbuch B: Drug uptake systems in liver and kidney: a historic perspective. Clinical Pharmacology and Therapeutics 2010, 87:39-47.

40. Efferth T, Benakis A, Romero MR, Tomicic M, Rauh R, Steinbach D, Häfer R, Stamminger T, Oesch F, Kaina B, Marschall M: Enhancement of cytotoxicity of artemisinins toward cancer cells by ferrous iron. Free Radical Biology and Medicine 2004, 37:998-1009.

41. Kelter G, Steinbach D, Konkimalla VB, Tahara T, Taketani S, Fiebig HH, Efferth $T$ : Role of transferrin receptor and the $A B C$ transporters $A B C B 6$ and $A B C B 7$ for resistance and differentiation of tumor cells towards artesunate. PLoS One 2007, 2:e798.

42. Warburg O: On the origin of cancer cells. Science 1956, 123:309-314.

43. Hühn E, Buchholz HG, Shazly G, Maus S, Thews O, Bausbacher N, Rösch F, Schreckenberger $M$, Langguth P: Predicting the in vivo release from a liposomal formulation by IVIVC and non-invasive positron emission tomography imaging. European Journal of Pharmaceutical Sciences 2010, 41:71-77.

44. Couturier O, Luxen A, Chatal J-F, Vuillez J-P, Rigo P, Hustinx R: Fluorinated tracers for imaging cancer with positron emission tomography. European Journal of Nuclear Medicine and Molecular Imaging 2004, 31:1182-1206.

45. Carrasco N: lodide transport in the thyroid gland. Biochimica et Biophysica Acta 1993, 1154:65-82.

46. Tazebay U, Wapnir I, Levy O, Tazebay UH, Wapnir IL, Levy O, Dohan O, Zuckier LS, Zhao QH, Deng HF, Amenta PS, Fineberg S, Pestell RG, Carrasco N: The mammary gland iodide transporter is expressed during lactation and in breast cancer. Nature Medicine 2000, 6:871-878.

47. Ballinger JR, Hua HA, Berry BW, Firby P, Boxen I: 99mTc-sestamibi as an agent for imaging P-glycoprotein-mediated multi-drug resistance: in vitro and in vivo studies in a rat breast tumour cell line and its doxorubicin-resistant variant. Nuclear Medicine Communications 1995, 16:253-257.

48. Cordobes MD, Starzec A, Delmon-Moingeon L, Blanchot C, Kouyoumdjian JC, Prévost G, Caglar M, Moretti JL: Technetium-99msestamibi uptake by human benign and malignant breast tumor cells: 
correlation with mdr gene expression. Journal of Nuclear Medicine 1996, 37:286-289.

49. Chen WS, Luker KE, Dahlheimer JL, Pica CM, Luker GD, Piwnica-Worms D: Effects of MDR1 and MDR3 P-glycoproteins, MRP1 and BCRP/MXR/ABCP on transport of Tc-99m-tetrofosmin. Biochemical Pharmacology 2000, 60:413-426.

50. Vecchio SD, Ciarmiello A, Potena MI, Carriero MV, Mainolfi C, Botti G, Thomas R, Cerra M, D'Aiuto G, Tsuruo T, Salvatore M: In vivo detection of multidrug resistance (MDR1) phenotype by technetium-99m-sestamibi scan in untreated breast cancer patients. European Journal of Nuclear Medicine 1997, 24:150-159.

51. Del Vecchio S, Ciarmiello A, Pace L, Potena MI, Carriero MV, Mainolfi C, Thomas R, D'Aiuto G, Tsuruo T, Salvatore M: Fractional retention of technetium-99m-sestamibi as an index of P-glycoprotein expression in untreated breast cancer patients. Journal of Nuclear Medicine 1997, 38:1348-1351

52. Kostakoglu L, Elahi N, Kiratlï P, Ruacan S, Sayek I, Baltalï E, Sungur A, Hayran M, Bekdik CF: Clinical validation of the influence of P-glycoprotein on technetium-99m-sestamibi uptake in malignant tumors. Journal of Nuclear Medicine 1994, 38:1003-1008.

53. Fukumoto M, Yoshida D, Hayase N, Kurohara A, Akagi N, Yoshida S: Scintigraphic prediction of resistance to radiation and chemotherapy in patients with lung carcinoma: technetium 99m-tetrofosmin and thallium-201 dual single photon emission computed tomography study. Cancer 1999, 86:1470-1479.

54. Hendrikse NH, Franssen EJ, van der Graaf WT, Meijer C, Piers DA, Vaalburg W, de Vries EG: $99 \mathrm{mTC}$-sestamibi is a substrate for Pglycoprotein and the multidrug resistance-associated protein. British Journal of Cancer 1998, 77:353-358.

55. Kao CH, Ho YJ, Shen YY, Lee JK: Evaluation of chemotherapy response in patients with small cell lung cancer using Technetium-99m-tetrofosmin. Anticancer Research 1999, 19:2311-5.

56. Kao A, Shuin SC, Hsu NY, Sun SS, Lee CC, Lin CC: Technetium-99m methoxyisobuthylisonitrile chest imaging for small-cell lung cancer. Annals of Oncology 2001, 12:1561-1566.

57. Liang JA, Shiau YC, Yang SN, Lin FJ, Lin CC, Kao A, Lee CC: Using technetium-99m-tetrofosmin scan to predict chemotherapy response of malignant lymphomas, compared with P-glycoprotein and multidrug resistance related protein expression. Oncology Reports 2002, 9:307-12.

58. Thacker J, Stretch A, Stephens MA: The induction of thioguanine-resistant mutants of Chinese hamster cells by gamma-rays. Mutatation Research 1977, 42:313-326.

59. Osmak M, Perovic S: Multiple fractions of gamma rays induced resistance to cis-dichloro-diammineplatinum (II) and methotrexate in human HeLa cells. International Journal of Radiation Oncology Biology and Physics 1989, 16:1537-1541.

60. Hill BT, Deuchars K, Hosking LK, Ling V, Whelan RD: Overexpression of Pglycoprotein in mammalian tumor cell lines after fractionated $X$ irradiation in vitro. Journal of the National Cancer Institute 1990, 82:607-612.

61. McClean S, Hill BT: Evidence of post-translational regulation of Pglycoprotein associated with the expression of a distinctive multiple drug-resistant phenotype in Chinese hamster ovary cells. European Journal of Cancer 1993, 29A:2243-2248.

62. Mattern J, Efferth T, Volm M: Overexpression of P-glycoprotein in human lung carcinoma xenografts after fractionated irradiation in vivo. Radiation Research 1991, 127:335-338.

63. Stammler G, Pommerenke EW, Masanek U, Mattern J, Volm M: Messenger RNA expression of resistance factors in human tumor cell lines after single exposure to radiation. Journal of Experimental Therapeutics and Oncology 1996, 1:39-48.

64. Harvie RM, Davey MW, Davey RA: Increased MRP expression is associated with resistance to radiation, anthracyclines and etoposide in cells treated with fractionated gamma-radiation. International Journal of Cancer 1997, 73:164-167.

65. Bottke D, Koychev D, Busse A, Heufelder K, Wiegel T, Thiel E, Hinkelbein W, Keilholz U: Fractionated irradiation can induce functionally relevant multidrug resistance gene and protein expression in human tumor cell lines. Radiation Research 2008, 170:41-48.

66. Denko NC: Hypoxia, HIF1 and glucose metabolism in the solid tumour. Nature Reviews Cancer 2008, 8:705-713.
67. Nakae $T$, Uto $Y$, Tanaka M, Shibata H, Nakata E, Tominaga M, Maezawa H, Hashimoto T, Kirk KL, Nagasawa H, Hori H: Design, synthesis, and radiosensitizing activities of sugar-hybrid hypoxic cell radiosensitizers. Bioorganic and Medicinal Chemistry 2008, 16:675-682.

68. Anderson P, Aguilera D, Pearson M, Woo S: Outpatient chemotherapy plus radiotherapy in sarcomas: improving cancer control with radiosensitizing agents. Cancer Control 2008, 15:38-46.

69. Maity A, Tuttle SW: 2-Deoxyglucose and radiosensitization: teaching an old DOG new tricks? Cancer Biology and Therapy 2006, 5:824-826.

70. Dwarakanath BS: Cytotoxicity, radiosensitization, and chemosensitization of tumor cells by 2-deoxy-D-glucose In vitro. Journal of Cancer Research and Therapeutics 2009, 5:27-31.

71. El-Khoury V, Breuzard G, Fourré N, Dufer J: The histone deacetylase inhibitor trichostatin A downregulates human MDR1 (ABCB1) gene expression by a transcription-dependent mechanism in a drug-resistant small cell lung carcinoma cell line model. British Journal of Cancer 2007, 97:562-573.

72. McCollum AK, TenEyck CJ, Stensgard B, Morlan BW, Ballman KV, Jenkins RB, Toft DO, Erlichman C: P-Glycoprotein-mediated resistance to Hsp90directed therapy is eclipsed by the heat shock response. Cancer Research 2008, 68:7419-7427.

73. Pham AN, Wang J, Fang J, Gao X, Zhang Y, Blower PE, Sadée W, Huang Y: Pharmacogenomics approach reveals MRP1 (ABCC1)-mediated resistance to geldanamycins. Pharmaceutical Research 2009, 26:936-945.

74. García MG, Alaniz LD, Cordo Russo Rl, Alvarez E, Hajos SE: PI3K/Akt inhibition modulates multidrug resistance and activates NF-kappaB in murine lymphoma cell lines. Leukemia Research 2009, 33:288-296.

75. Tazzari PL, Cappellini A, Ricci F, Evangelisti C, Papa V, Grafone T, Martinelli G, Conte R, Cocco L, McCubrey JA, Martelli AM: Multidrug resistanceassociated protein 1 expression is under the control of the phosphoinositide 3 kinase/Akt signal transduction network in human acute myelogenous leukemia blasts. Leukemia 2007, 21:427-438.

76. Furtado LM, Somwar R, Sweeney G, Niu W, Klip A: Activation of the glucose transporter GLUT4 by insulin. Biochemistry and Cell Biology 2002, 80:569-578.

77. Cantuaria G, Fagotti A, Ferrandina G, Magalhaes A, Nadji M, Angioli R, Penalver M, Mancuso S, Scambia G: GLUT-1 expression in ovarian carcinoma: association with survival and response to chemotherapy. Cancer 2001, 92:1144-1150.

78. Alvarez Al, Real R, Perez M, Mendoza G, Prieto JG, Merino G: Modulation of the activity of $A B C$ transporters (P-glycoprotein, MRP2, BCRP) by flavonoids and drug response. Journal of Pharmaceutical Sciences 2010, 22:598-617.

79. Choi JS, Choi BC, Kang KW: Effect of resveratrol on the pharmacokinetics of oral and intravenous nicardipine in rats: possible role of $\mathrm{P}$ glycoprotein inhibition by resveratrol. Pharmazie 2009, 64:49-52.

80. Baumert C, Hilgeroth A: Recent advances in the development of P-gp inhibitors. Anticancer Agents in Medicinal Chemistry 2009, 9:415-436.

81. Tiwar AK, Sodani K, Dai CL, Ashby CR Jr, Chen ZS: Revisiting the ABCs of Multidrug Resistance in Cancer Chemotherapy. Current Pharmaceutical Biotechnology 2010.

82. Molnár J, Engi H, Hohmann J, Molnár P, Deli J, Wesolowska O, Michalak K, Wang Q: Reversal of multidrug resitance by natural substances from plants. Current Topics in Medicinal Chemistry 2010, 10:1757-1768.

83. Eichhorn T, Efferth T: P-glycoprotein and its Inhibition in Tumors by Phytochemicals derived from Traditional Chinese Medicine. Journal of Ethnopharmacology 2011.

84. Versantvoort $\mathrm{CH}$, Broxterman HJ, Lankelma J, Feller N, Pinedo HM: Competitive inhibition by genistein and ATP dependence of daunorubicin transport in intact MRP overexpressing human small cell lung cancer cells. Biochemical Pharmacology 1994, 48:1129-1136.

85. Nabekura T, Yamaki T, Ueno K, Kitagawa S: Inhibition of P-glycoprotein and multidrug resistance protein 1 by dietary phytochemicals. Cancer Chemotherapy and Pharmacology 2008, 62:867-873.

86. Wesolowska O, Wisniewski J, Sroda K, Krawczenko A, Bielawska-Pohl A Paprocka M, Dus D, Michalak K: 8-Prenylnaringenin is an inhibitor of multidrug resistance-associated transporters, P-glycoprotein and MRP1. European Journal of Pharmacology 2010, 644:32-40.

87. Ahmed-Belkacem A, Pozza A, Macalou S, Pérez-Victoria JM, Boumendjel A, Di Pietro A: Inhibitors of cancer cell multidrug resistance mediated by 
breast cancer resistance protein (BCRP/ABCG2). Anticancer Drugs 2006, 17:239-243.

88. Boumendjel A, McLeer-Florin A, Champelovier P, Allegro D, Muhammad D, Souard F, Derouazi M, Peyrot V, Toussaint B, Boutonnat J: A novel chalcone derivative which acts as a microtubule depolymerising agent and an inhibitor of P-gp and BCRP in in-vitro and in-vivo glioblastoma models. BMC Cancer 2009, 9:242.

89. Farabegoli F, Papi A, Bartolini G, Ostan R, Orlandi M: (-)-Epigallocatechin-3gallate downregulates Pg-P and BCRP in a tamoxifen resistant MCF-7 cell line. Phytomedicine 2010, 17:356-362.

90. Mitchell JL, Judd GG, Diveley RR Jr, Choe CY, Leyser A: Involvement of the polyamine transport system in cellular uptake of the radioprotectants WR-1065 and WR-33278. In Carcinogenesis. Volume 16. Lond:; 1995:3063-3068.

91. Newton GL, Aguilera JA, Kim T, Ward JF, Fahey RC: Transport of aminothiol radioprotectors into mammalian cells: passive diffusion versus mediated uptake. Radiation Research 1996, 146:206-215.

92. Quiñones HI, List AF, Gerner EW: Selective Exclusion by the Polyamine Transporter as a Mechanism for Differential Radioprotection of Amifostine Derivatives. Clinical Cancer Research 2008, 8:1295-1300.

93. Lamperti A, Ziskin MC, Bergey E, Gorlowski J, Sodicoff M: Transdermal absorption of radioprotectors in the rat using permeation-enhancing vehicles. Radiation Research 1990, 124:194-200.

94. Maier P, Fleckenstein K, Li L, Laufs S, Zeller WJ, Baum C, Fruehauf S, Herskind C, Wenz F: Overexpression of MDR1 using a retroviral vector differentially regulates genes involved in detoxification and apoptosis and confers radioprotection. Radiation Research 2006, 166:463-473.

95. Hilgendorf C, Spahn-Langguth H, Rhedin M, Regårdh CG, Löwenadler B, Langguth P: Selective downregulation of the MDR1 gene product in Caco-2 cells by stable transfection to prove its relevance in secretory drug transport. Molecular Pharmaceutics 2005, 2:64-73.

96. Lebrun F, Benderitter M, Berroud A, Voisin P, Griffiths NM: Potential role of the membrane in the development of intestinal cellular damage after whole-body gamma irradiation of the rat. Canadian Journal of Physiology and Pharmacology 2002, 80:686-693.

97. Kaempf-Rotzolla DE, Traberc MG, Arai H: Vitamin E and transfer proteins. Current Opinion in Lipidology 2003, 14:249-254.

98. Lemaire-Ewing S, Desrumaux C, Neel D, Lagrost L: Vitamin E transport, membrane incorporation and cell metabolism: Is a-tocopherol in lipid rafts an oar in the lifeboat? Molecular Nutrition and Food Research 2010, 54:631-640.

doi:10.1186/1748-717X-6-59

Cite this article as: Efferth and Langguth: Transport processes of radiopharmaceuticals and -modulators. Radiation Oncology 2011 6:59.

\section{Submit your next manuscript to BioMed Central and take full advantage of:}

- Convenient online submission

- Thorough peer review

- No space constraints or color figure charges

- Immediate publication on acceptance

- Inclusion in PubMed, CAS, Scopus and Google Scholar

- Research which is freely available for redistribution

Submit your manuscript at www.biomedcentral.com/submit

C Biomed Central 